\title{
A Versatile Strategy for Surface Functionalization of Hydrophobic Nanoparticle by Boronic Acid Modified Polymerizable Diacetylene Derivatives
}

\author{
Shiwei Gu, Chang Guo, Hui Wang, Guangjun Tian, Suying Xu* and Leyu Wang* \\ State Key Laboratory of Chemical Resource Engineering, Beijing University of Chemical Technology, Beijing, China
}

The flourishing advancements in nanotechnology significantly boost their application in biomedical fields. Whereas, inorganic nanomaterials are normally prepared and capped with hydrophobic ligands, which require essential surface modification to increase their biocompatibility and endow extra functions. Phenylboronic acid derivatives have long been known for its capacity for selective recognition of saccharides. Herein, we demonstrated a versatile surface modification strategy to directly convert hydrophobic inorganic nanocrystals into water-dispersible and targeting nanocomposites by employing boronic acid modified photo-polymerizable 10,12-pentacosadiynoicacid and further explore its potentials in selective cancer cell imaging.

Keywords: boronic acid, photo polymerization, surface functionalization, cancer cell targeting, fluorescence imaging

\section{INTRODUCTION}

In the past two decades, the vast advancements in nanotechnology significantly boost their application in biomedical fields, by taking advantage of rich choices of inorganic nanoparticles that possess as outstanding optical, magnetic, and electrical features. For instance, luminescence nanocomposites have been utilized for molecular recognition, real-time tracking and cell labeling (Liu et al., 2012; Chen et al., 2015; Lu et al., 2015; Arshad et al., 2016; Guo et al., 2019; Nifontova et al., 2019). Magnetic nanomaterials have been employed for magnetic resonance imaging, magnetic guided drug delivery (Mahmoudi and Hadjipanayis, 2014; Zhang et al., 2018; Zhu et al., 2018). Photothermal responsive nanocrystals have displayed great potentials in light-guided drug delivery and photothermal treatment of tumors (Lu et al., 2017; Zhao et al., 2017; Wang et al., 2018; Vines et al., 2019). Whereas, these inorganic nanomaterials are normally prepared in organic solvents and capped with hydrophobic ligands, which require essential surface modification prior to further use. To this end, various methods (Chen et al., 2008; Nurunnabi et al., 2010; Dong et al., 2011; Lu et al., 2011; Deng et al., 2012; Huang et al., 2013) have been developed such as ligand exchange, layer-by-layer strategy, silanization, amphiphilic polymer coating, biomimetic functionalization, in-situ polymerization, and so on. Ideally, surface engineering shall well-maintain intrinsic properties of inorganic nanocrystals as well as convert them into hydrophilic, biocompatible and functional nanocomposites, meanwhile, the surface modification protocols shall be simple, straightforward without tedious procedures. In this regard, it still lacks versatile and time-efficient surface engineering strategy that allow for directly converting hydrophobic inorganic 
nanocrystals into water-dispersible and functional nanocomposites for biomedical utilization.

With respect to biomedical application, the specific targeting ability was of crucial importance. Apart from enhanced permeability and retention effect of nanomaterials, the active targeting is always required for site-specific labeling and drug delivery (Choi et al., 2011; Zhao et al., 2015; Hui et al., 2019; Li et al., 2019; Sun et al., 2019; Yan et al., 2019). Phenylboronic acid derivatives have long been known for its capacity for selective recognition of saccharides through covalent formation of boronate ester with 1,2 and 1,3 cis-diols presenting on many saccharides (Xu et al., 2010; Nishiyabu et al., 2011; Wang et al., 2014; Sun et al., 2018). As such, fluorescent boronic acid derivatives were developed to monitor glucose variation and detect glycated proteins. Moreover, recent findings revealed that changes of glycan expression on cell surface are closely related with tumor metastasis. For instance, sialic acid moieties have been found to over-expressed in many cancerous cells (Matsumoto et al., 2010). On basis of such observation, boronic acid moieties have been utilized as sitespecific labels for targeting cancerous cells (Liu et al., 2011; Wu et al., 2015). Inspired by these achievements, we proposed to use photo-polymerizable 10,12-pentacosadiynoic acid derivatives containing boronic acid moiety (PCDA-BA) for hydrophobic inorganic nanocrystals surface engineering, which in one aspect, would directly convert hydrophobic nanocrystals into waterdispersible ones and in another aspect, endow the resulting nanocomposites with site-specific binding properties (Figure 1). The results demonstrated that the photo-polymerizable property of PCDA allows for straightforward phase transfer of various types of inorganic nanoparticles, suggesting the generality of this method, and moreover, as a proof-of-concept, such surface modification strategy could be readily tailoring the surface functions with boronic acid moieties, resulting in selective labeling of cancerous cells.

\section{MATERIALS AND METHODS}

\section{Materials}

10,12-Pentacosadiynoicacid (PCDA), N-Hydroxysuccinimide (NHS) and sodium stearate were purchased from Alfa Aesar. Carbodiimide (EDC), hydrofluoric acid (HF), 1-dodecanethiol, and indium (III) nitrate trihydrate was obtained from Aladdin. Oleic acid (OA), oleylamine (OAm), and 1-octadecene (ODE) were purchased from Alfa Aesar. 4-Aminophenyl boronic acid hydrochloride was gained from Sukailu Chemical Reagent Company. 2,2-Dimethyl-1,3-propanediol and silver acetate were purchased from Sinoreagent Chemical Reagent Company. Sulfur and $\mathrm{Na}_{2} \mathrm{~S} \cdot 9 \mathrm{H}_{2} \mathrm{O}$ were gained from XLHG Chemicals Co. $\mathrm{Fe}\left(\mathrm{NH}_{4}\right)_{2}\left(\mathrm{SO}_{4}\right)_{2} \cdot 6 \mathrm{H}_{2} \mathrm{O}$ and $\mathrm{NaOH}$ were purchased from Beijing Chem Works. $\mathrm{ZnCl}_{2} \cdot 4 \mathrm{H}_{2} \mathrm{O}, \mathrm{Cu}\left(\mathrm{NO}_{3}\right)_{2} \cdot 5 \mathrm{H}_{2} \mathrm{O}$, and $\mathrm{AgNO}_{3}$ were obtained from Tianjin GuangFu Chemicals Co., Tianjin FuChen Chemicals Co., and Innochem Chemicals Co., respectively. $\mathrm{N}, \mathrm{N}$-Dibutyldithiocarbamic acid $\left(\mathrm{HS}_{2} \mathrm{CNBut}_{2}\right)$ is obtained from Beijing keao Technology Co., Ltd. All the reagents were of analytical grade and used as received without further purification.

\section{Characterization}

TEM images were obtained on a Hitachi H-800 transmission electron microscope operating at $200 \mathrm{kV}$. Powder XRD patterns were carried out on a Bruker AXS D8-Advanced Xray diffractometer with $\mathrm{Cu} \mathrm{K \alpha}$ radiation $(\lambda=1.5418 \AA)$. Absorption spectra were obtained using a UV-3600 UV-visNIR spectrophotometer (Shimadzu) equipped with a plotter unit. Optical properties of the NPs were characterized using a Hitachi F-4600 fluorescence spectrophotometer equipped with a plotter unit and a quartz cell $(1 \mathrm{~cm} \times 1 \mathrm{~cm})$. DLS measurements were carried out using a Zetasizer Nano-ZS90 zeta and size analyzer from Malvern. All ${ }^{1} \mathrm{H}$ and ${ }^{13} \mathrm{C}$ NMR spectra were recorded on a Bruker Avance $400 \mathrm{MHz}$ spectrometer.

\section{Synthesis of Ag Nanoparticle (Ag NPs)}

Six milliliters of ODE and $4 \mathrm{~mL}$ of OAm were added into a $50 \mathrm{~mL}$ three flask and heated up to $190^{\circ} \mathrm{C}$ under nitrogen atmosphere. Then the sliver precursor was quickly injected and maintained at this temperature for $30 \mathrm{~min}$. Then solution was cooled to room temperature naturally, and the product was collected by centrifugation. The final products were redispersed in $2 \mathrm{~mL}$ of chloroform. The sliver precursor obtained by dissolving silver acetate in ethanol.

\section{Synthesis of Au Nanoparticle (Au NPs)}

Similar to that for preparation of Au NPs, $6 \mathrm{~mL}$ of ODE and $4 \mathrm{~mL}$ of OAm were added into a $50 \mathrm{~mL}$ three flask and heated up to $160^{\circ} \mathrm{C}$ under nitrogen atmosphere, followed by quick injection of gold precursor, which maintained at $160^{\circ} \mathrm{C}$ for $30 \mathrm{~min}$. The solution was cooled to room temperature, and the product was collected by centrifugation. The final products were redispersed in $2 \mathrm{~mL}$ of chloroform. The Au precursor obtained by $\mathrm{HAuCl}_{4}$ dissolved in ethanol.

\section{Synthesis of $\mathrm{Cu}_{7} \mathrm{~S}_{4}$ Nanoparticle}

Six milliliters of ODE and $4 \mathrm{~mL}$ of OAm were added into a $50 \mathrm{~mL}$ three flask and heated up to $190^{\circ} \mathrm{C}$ under a protective nitrogen atmosphere. Then the precursor of copper was injected into the three flask and maintained this temperature for $15 \mathrm{~min}$, which was cooled to room temperature, and the products were collected by centrifugation. The final products were redispersed in $2 \mathrm{~mL}$ of chloroform. The $\mathrm{Cu}$ precursor obtained by $\mathrm{Cu}\left(\mathrm{NO}_{3}\right)_{3}$ and $\left(\mathrm{HS}_{2} \mathrm{CNBut}_{2}\right)$ dissolved in ethanol.

\section{Synthesis of $\mathrm{NaYF}_{4}: \mathrm{Yb}^{3+}-\mathrm{Er}^{3+}$ Nanoparticle}

Firstly, prepared of $\mathrm{NaYF}_{4}: \mathrm{Yb}^{3+}-\mathrm{Er}^{3+}$ nanoparticles, sodium stearate $(0.35 \mathrm{~g})$, a blended solution of OA $(7 \mathrm{~mL})$, and ODE $(7 \mathrm{~mL})$ were added into a three-necked flask under ultrasonic condition. Then, the HF-oleylamine solution $(1.05 \mathrm{~mL})$ and the precursor of rare-earth solution $(3 \mathrm{~mL})$ were fastly injected into the flask and stay at $90^{\circ} \mathrm{C}$ for $20 \mathrm{~min}$. Subsequently, the reaction solution was rise temperature to $180^{\circ} \mathrm{C}$ and hold $10 \mathrm{~min}$. Finally, the reaction solution was heated to $310^{\circ} \mathrm{C}$ and kept for $1 \mathrm{~h}$ under a protective nitrogen flow. The solution was cooled down to $80^{\circ} \mathrm{C}$ and through centrifugation the products was obtained. The final products were redispersed in $2 \mathrm{~mL}$ of chloroform. 


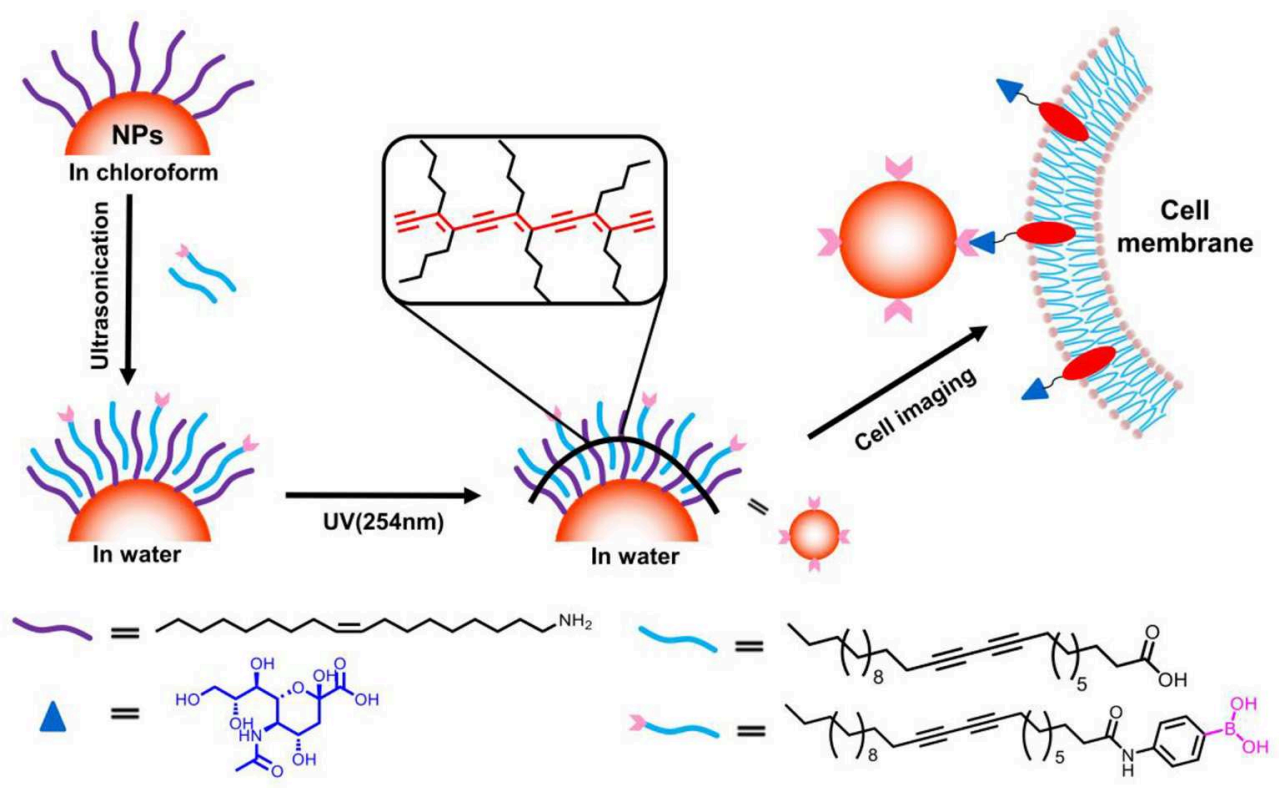

FIGURE 1 | Schematic illustration for surface coating of hydrophobic nanocrystals with boronic acid modified PCDA and its potential for selective cancer cell imaging.

\section{Synthesis of $\mathrm{Fe}_{3} \mathrm{O}_{4}$ Nanoparticle}

$\mathrm{Fe}_{3} \mathrm{O}_{4}$ nanoparticles were prepared by the hydrothermal method. $\mathrm{NaOH}(1 \mathrm{~g})$ and ultrapure water $(6 \mathrm{~mL})$ and ethyl alcohol $(10 \mathrm{~mL})$ were added into a $50 \mathrm{~mL}$ beaker. Subsequently, OA $(10 \mathrm{~mL})$ were injected dropwise. Meanwhile, $\mathrm{Fe}\left(\mathrm{NH}_{4}\right)_{2}\left(\mathrm{SO}_{4}\right)_{2}$. $\mathrm{H}_{2} \mathrm{O}(0.784 \mathrm{~g})$ dissolved into of $\mathrm{H}_{2} \mathrm{O}(10 \mathrm{~mL})$ was dropwise added into the beaker, and the transparent solution rapidly became turbid. Finally, the suspension was transferred into a teflon lined autoclave $(45 \mathrm{~mL})$ and hydrothermally treated at $220^{\circ} \mathrm{C}$ for $6 \mathrm{~h}$. After naturally cooling to room temperature, the thus-formed black precipitates were separated through centrifugation, and the final products were redispersed in 2 $\mathrm{mL}$ chloroform.

\section{Synthesis of ZnS-AgInS 2 (ZAIS) Fluorescent Quantum Dot}

$\mathrm{ZnS}-\mathrm{AgInS}_{2}$ quaternary fluorescent quantum dots were prepared via hot-inject method. Firstly, the $0.1025 \mathrm{mmol}$ of indium (III) precursor, $0.5 \mathrm{mmol}$ of $\mathrm{ZnCl}_{2}, 10 \mathrm{~mL}$ of $\mathrm{ODE}$, and $1 \mathrm{~mL}$ of DDT were added into a $50 \mathrm{~mL}$ three flask, then the mixture was heated up to $140^{\circ} \mathrm{C}$ and kept at this temperature for $15 \mathrm{~min}$ under an $\mathrm{N}_{2}$ atmosphere. Secondly, $2 \mathrm{~mL}$ of sulfur precursor with various concentrations was quickly injected into this solution and heated up to $200^{\circ} \mathrm{C}$. After $10 \mathrm{~min}, 2 \mathrm{~mL}$ of silver precursor was injected into the three flask, then the mixed solution was elevated to and maintained at $180^{\circ} \mathrm{C}$ for $60 \mathrm{~min}$. Finally, the products were centrifuged at $3,000 \mathrm{rpm}$ for $6 \mathrm{~min}$ to remove large particles. Fluorescent $\mathrm{ZnS}-\mathrm{AgInS}_{2}$ quantum dots were separated from the supernatant by methanol, followed by centrifugation for $10 \mathrm{~min}$ at $8,000 \mathrm{rpm}$. The final products were redispersed in $2 \mathrm{~mL}$ of chloroform.
Indium (III) precursor was obtained by mixing $1 \mathrm{mmol}$ of indium (III) nitrate trihydrate with $12 \mathrm{mmol}$ of stearic acid at $140^{\circ} \mathrm{C}$ for $4 \mathrm{~h}$, then naturally cooled down to room temperature. The silver precursor was prepared by dissolving $0.25 \mathrm{mmol}$ of silver nitrate in a mixture solvent of $9 \mathrm{~mL}$ of EtOH of and $1 \mathrm{~mL}$ of $\mathrm{OAm}$. The sulfur precursor was acquired by dissolving sublimed sulfur $(1.6,2.4,4.8$, and $9.6 \mathrm{mg}$ ) in mixture solution containing $1 \mathrm{~mL}$ of OAm and $1 \mathrm{~mL}$ of ODE.

\section{Synthesis of 4-Aminophenylboronic Acid Modified Diacetylene Monomer (PCDA-BA)}

The synthetic scheme for PCDA-BA (Compound 4) was listed in Supplementary Figure 1. Specifically, $300 \mathrm{mg}(2.61 \mathrm{mmol})$ of NHS and $750 \mathrm{mg}(2 \mathrm{mmol})$ of PCDA were dissolved with $20 \mathrm{~mL}$ of $\mathrm{CH}_{2} \mathrm{Cl}_{2}$ in $50 \mathrm{~mL}$ three flask and stirred for $30 \mathrm{~min}$, thereafter, $800 \mathrm{mg}(4.17 \mathrm{mmol})$ of EDC was added under nitrogen flow and stirred at room temperature for $16 \mathrm{~h}$. Then the mixed solution was filtered, followed by evaporation of $\mathrm{CH}_{2} \mathrm{Cl}_{2}$, and the product was redispersed in $25 \mathrm{~mL}$ of $\mathrm{CHCl}_{3}$ and washed it four times with saturated $\mathrm{NaCl}$ aqueous. After that the solution was evaporated, the compound $\mathbf{1}$ was obtained.

Secondly, $347 \mathrm{mg}(2 \mathrm{mmol})$ of 4 -aminophenylboronic acid $\mathrm{HCl}$ and $500 \mathrm{mg}(4.71 \mathrm{mmol})$ of sodium carbonate were dissolved in $25 \mathrm{~mL} \mathrm{CHCl} 3$ and stirred at room temperature for $30 \mathrm{~min}$, thereafter, $208 \mathrm{mg}$ (2 mmol) of 2,2-dimethyl-1,3-propanediol and $1,000 \mathrm{mg}(7 \mathrm{mmol})$ sodium sulfate anhydrous added into this solution under a protective nitrogen flow stirred at room temperature for $3 \mathrm{~h}$. After filtering the insoluble inorganic salts, compound 2 ( $423.7 \mathrm{mg}, 95 \%)$ was obtained via evaporation under reduced pressure. ${ }^{1} \mathrm{H}$ NMR $\left(400 \mathrm{MHz}, \mathrm{CDCl}_{3}\right) \delta(\mathrm{ppm})$ $1.01(\mathrm{~s}, 6 \mathrm{H}), 3.76(\mathrm{~s}, 4 \mathrm{H}), 6.70(\mathrm{~d}, J=8.4 \mathrm{~Hz}, 2 \mathrm{H}), 7.65(\mathrm{~d}, J=$ $8.3 \mathrm{~Hz}, 2 \mathrm{H})$. 
Finally, the compound $\mathbf{1}$ and $\mathbf{2}$ were dispersed in $25 \mathrm{~mL}$ of $\mathrm{CH}_{2} \mathrm{Cl}_{2}$ and stirred at temperature for $24 \mathrm{~h}$. After that the solvent being evaporated, compound 3 (642.3 mg, 64\%), was obtained by silica gel column $\left(\mathrm{CH}_{2} \mathrm{Cl}_{2} / \mathrm{CH}_{3} \mathrm{OH}, 90: 5\right) .{ }^{1} \mathrm{H}$ NMR $(400 \mathrm{MHz}$, $\left.\mathrm{CDCl}_{3}\right) \delta(\mathrm{ppm}) 0.86(\mathrm{t}, J=6.9 \mathrm{~Hz}, 3 \mathrm{H}), 1.03(\mathrm{~s}, 6 \mathrm{H}), 1.24-1.55$ $(\mathrm{m}, 32 \mathrm{H}), 2.21-2.27(\mathrm{~m}, 4 \mathrm{H}), 2.38-2.45(\mathrm{~m}, 2 \mathrm{H}), 3.7(\mathrm{~s}, 4 \mathrm{H}), 7.51$ (d, $J=8.3 \mathrm{~Hz}, 2 \mathrm{H}), 7.79(\mathrm{~d}, J=8.2 \mathrm{~Hz}, 2 \mathrm{H})$.

Compound 4 (PCDA-BA) was obtained by further treating compound 3 (561 mg, $1 \mathrm{mmol}$ ) with aqueous potassium hydrogen fluoride $(3 \mathrm{~mL}, 5.64 \mathrm{mmol})$ in $\mathrm{MeOH}(7 \mathrm{~mL})$ under stirring at $25^{\circ} \mathrm{C}$ for $0.2 \mathrm{~h}$, which was concentrated by rotary evaporator and recrystallized by hot acetone (minimal volume to dissolve solid) and ether to afford corresponding potassium trifluoroborate solid. The potassium trifluoroborate solid $(0.5$ $\mathrm{mmol}, 277.5 \mathrm{mg}$ ) and sodium carbonate $(1.5 \mathrm{mmol}, 158.9 \mathrm{mg})$ were dissolved in water $(5 \mathrm{~mL})$ and acetonitrile $(10 \mathrm{~mL})$. The mixture then was stirred for $20 \mathrm{~h}$ under $25^{\circ} \mathrm{C}$. Then a mixed solution of saturated aqueous $\mathrm{NH}_{4} \mathrm{Cl}(8 \mathrm{~mL})$ and $1 \mathrm{M} \mathrm{HCl}(2 \mathrm{~mL})$ was added. The resulting solution was extracted by ethyl acetate $(3 \times 10 \mathrm{~mL})$. All of organic extracts were dried over sodium sulfate, filtered and concentrated under vacuo to afford PCDABA. ${ }^{1} \mathrm{H}$ NMR $\left(400 \mathrm{MHz}, \mathrm{CD}_{3} \mathrm{OD}\right) \delta(\mathrm{ppm}) 0.86(\mathrm{t}, J=6.7 \mathrm{~Hz}$, $3 \mathrm{H}), 1.23-1.57(\mathrm{~m}, 32 \mathrm{H}), 2.18-2.26(\mathrm{~m}, 4 \mathrm{H}), 2.34-2.41(\mathrm{~m}, 2 \mathrm{H})$, 7.56-7.72(4H); MS (ESI, negative ion); calc. $\mathrm{C}_{31} \mathrm{H}_{48} \mathrm{BNO}_{3}, \mathrm{~m} / \mathrm{z}$ 493.37, found, 492.36 .

\section{Procedures for Preparing Hydrophilic Nanocomposites Containing Single NPs}

In a typical experiment, $0.005 \mathrm{~mol}$ of PCDA and $5 \mathrm{mg}$ hydrophobic nanoparticles (Ag NPs, Au NPs, $\mathrm{Fe}_{3} \mathrm{O}_{4}$ NPs and ZAIS) dissolved in $1 \mathrm{~mL}$ of chloroform, was added in a $10 \mathrm{~mL}$ of $0.004 \mathrm{M} \mathrm{NaOH}$ aqueous solution under ultrasonication $(350 \mathrm{~W}, 12 \mathrm{~min})$. Then, the chloroform was evaporated at $50^{\circ} \mathrm{C}$ for $2 \mathrm{~h}$. Finally, hydrophilic nanoparticles were washed by ultrapure water and collected by centrifugation at $10,000 \mathrm{rpm}$ for $10 \mathrm{~min}$, which was redispersed into water, followed by UV irradiation treatment under 254-nm UV lamp for $30 \mathrm{~s}$. With respect to preparation of ZAIS@PCDA-BA, all the experiment conditions are identical only that $0.005 \mathrm{~mol}$ of a mixture of PCDA and PCDA-BA (PCDA-BA:/PCDA = 1:8) was used instead of pure PCDA.

\section{Preparations of Nanocomposites Containing Multiple Nanoparticles}

Hydrophilic nanocomposites containing multiple NPs were prepared with protocols similar to that containing single nanoparticle, but with variation of $\mathrm{NaOH}$ amount being used. Briefly, $0.005 \mathrm{~mol}$ of PCDA and $5 \mathrm{mg}$ hydrophobic nanoparticles dissolved in $1 \mathrm{~mL}$ of chloroform then the solution was added in $10 \mathrm{~mL}$ of $0.001 \mathrm{M} \mathrm{NaOH}$ aqueous solution under ultrasonication ( $350 \mathrm{~W}, 12 \mathrm{~min}$ ). Secondly, the chloroform was evaporated at $50^{\circ} \mathrm{C}$ for $2 \mathrm{~h}$. Finally, hydrophilic nanocomposites were washed by ultrapure water and collected by centrifugation at 10,000 rpm for $10 \mathrm{~min}$ and redispersed into water and under $254 \mathrm{~nm} \mathrm{UV}$ lamp irradiated $30 \mathrm{~s}$.

\section{Cytotoxicity Experiment}

Briefly, HepG2 cells attached to the bottom of 96-well-cell culture plate were incubated with different concentrations (0$300 \mu \mathrm{g} / \mathrm{mL}$ ) of sterilized ZAIS@PCDA-BA NCs in each well at $37^{\circ} \mathrm{C}$ for 24 or $48 \mathrm{~h}$, respectively. Then the cytotoxicity was measured by the methyl thiazolyltetrazolium (MTT) assay (Guo et al., 2018).

\section{Cell Imaging}

HepG2 cells were seeded in a glass bottom cell culture dish and cultured at $37^{\circ} \mathrm{C}$ overnight. Then the ZAIS@PCDA-BA NCs stock solution was added with a final concentration of $300 \mu \mathrm{g} / \mathrm{mL}$. The HepG2 cells were incubated with ZAIS@PCDABA NCs for different times $(2,4$, and $8 \mathrm{~h})$. As a control, the ZAIS@PCDA NCs were incubated with the HepG2 cells for $8 \mathrm{~h}$. Meanwhile, to verify the targeting ability of boronic acid moiety, $0.1 \mathrm{M}$ D-fructose was added as competitive component and coincubated with were incubated with the HepG2 cells for $8 \mathrm{~h}$ in the presence of ZAIS@PCDA-BA NCs. Then, the cells in glass bottom cell culture dish were washed with PBS (pH 7.4, $10 \mathrm{mM}$ ) and mixed with $4 \%$ paraformaldehyde solution for $15 \mathrm{~min}$. The luminescence imaging was conducted on TCS-SP8 confocal laser microscopes (Leica) equipped with a $488 \mathrm{~nm}$ laser.

\section{RESULTS AND DISCUSSION}

\section{Surface Modification of Hydrophobic NPs}

In view of the biomedical application of inorganic nanocrystals, a prerequisite is proper surface modification, which ensures biocompatibility as well as functionalities. 10,12pentacosadiynoic acid (PCDA) has long been used to form polymerized liposomes under UV irradiation and meanwhile, the polydiacetylene moiety can be a signaling unit, responsive toward external stimuli such as $\mathrm{pH}$ (Song et al., 2001), surfactants (Chen et al., 2010; Lee et al., 2011), and metal ions (Lee et al., 2009; Wen et al., 2016). Given that hydrophobic nanocrystals normally were capped with ligands contains long alkyl chain, we assumed 10, 12-pentacosadiynoic acid (PCDA) may serve as a phase transfer agent through hydrophobic-hydrophobic interaction. Indeed, such assumption was demonstrated to transfer hydrophobic upconversion nanoparticles into aqueous phase (Nsubuga et al., 2018). Moreover, the photo-polymerizable properties of PCDA could further anchor surface ligands as well as providing active sites for functionalization. Bearing this mind, initially we testify the feasibility of PCDA for phase transfer. In this regards, as shown in Figure 2, we adopted a series of hydrophobic nanoparticles, including noble mental ( $\mathrm{Au}, \sim 15 \mathrm{~nm} ; \mathrm{Ag}, \sim 12 \mathrm{~nm})$, inorganic mental sulfides $\left(\mathrm{Cu}_{7} \mathrm{~S}_{4}\right.$, $\sim 12 \mathrm{~nm}$ ), upconversion nanoparticles $\left(\mathrm{NaYF}_{4}: \mathrm{Yb}^{3+}-\mathrm{Er}^{3+}\right.$, $\sim 25 \mathrm{~nm}$ ), and magnetic nanoparticles $\left(\mathrm{Fe}_{3} \mathrm{O}_{4}, \sim 4 \mathrm{~nm}\right)$ to transfer them into aqueous phase, respectively. Hydrophobic nanoparticles and pristine PCDA were dissolved in chloroform 
and further added into $\mathrm{NaOH}$ aqueous solution to form emulsion under ultrasonication treatment. Under this progress, the PCDA spontaneous assembled onto the surface of hydrophobic nanoparticles. To achieve stable hydrophilic nanocomposites, the resulting solution was then irradiated under $254 \mathrm{~nm}$ UV-lamp, which can make PCDA anchored on the surface of hydrophobic nanoparticles through in-situ formation of polyacetylene. The strategy for hydrophobic nanoparticles surface engineering is facile and versatile. As evidenced by the results in Figure 2, transmission electron microscope (TEM) images indicated that the size and shape were maintained after surface engineering without aggregation being observed. Particle sizes measured by TEM were smaller than confirmed by dynamic light scattering
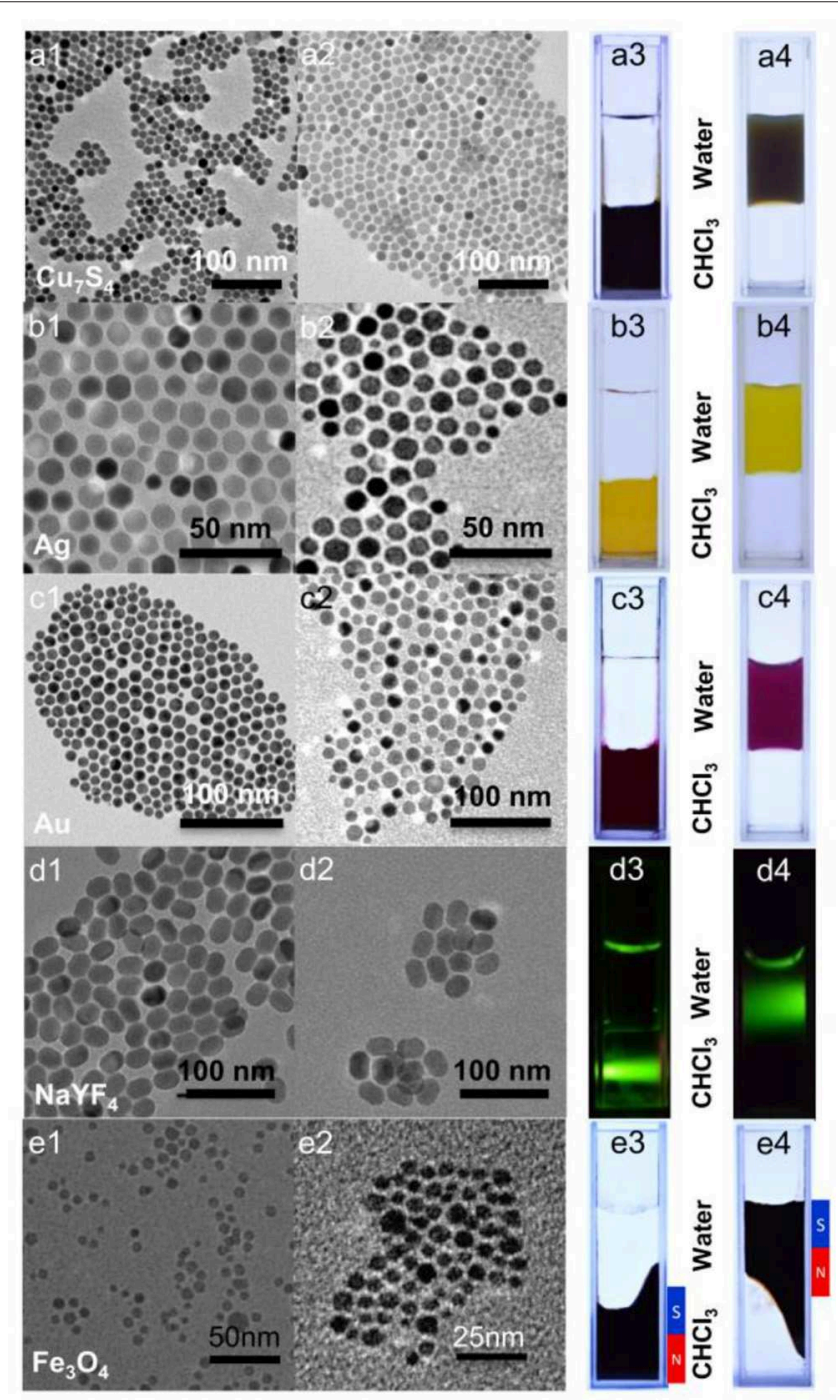

FIGURE 2 | TEM images (a1-e1, a2-e2) and photographs (a3-e3, a4-e4) of various types of inorganic nanocrystals (a): $\mathrm{Cu}_{7} \mathrm{~S}_{4}$, (b): Ag NPs, (c): Au NPs, (d): $\mathrm{NaYF}_{4}: \mathrm{Yb}^{3+} / \mathrm{Er}^{3+}$, and (e) $\mathrm{Fe}_{3} \mathrm{O}_{4}$ before $(1,3)$ and after $(2,4)$ surface engineering. Photograph 3 and 4: the top layer is water and the bottom layer is chloroform; (a-c) daylight; (d) 980-nm diode laser; (e) daylight with magnet.
(DLS), which likely caused by the carboxylic groups of PCDA interacted with water molecular and generated hydration layers. All types of hydrophobic nanocrystals were successfully transfer into aqueous phase without observable interference on the functional properties of inorganic nanoparticles including luminescence properties (Figure 2d) and magnetic properties (Figure 2e). Notably, all of hydrophobic nanoparticles were encapsulated in a one particle per micelle manner since the DLS sizes of nanocrystals merely changed before and after phase transfer process, shown in Supplementary Figure 2. It is worth noting that encapsulation of multiple nanoparticles could be readily achieved through variation the dosage of $\mathrm{NaOH}$ being used, as suggested in Supplementary Figure 3, which indicated that multifunctional nanocomposites could be constructed based on this strategy.

The PCDA molecule possesses a carboxylic group, which would stay at the outside of the resulting hydrophilic nanoparticles, thus allowing for further introduction of other functionalities. To evaluate such capability, we synthesized p-aminophenylboronic acid modified PCDA (PCDA-BA) by means of EDC/NHS coupling reaction (preparation procedures as well as the characterization was shown in Supplementary Figures 4-6). The obtained PCDA-BA would be further employed for surface modification of nanoparticles to achieve a selective targeting ability.

\section{Controllable Synthesis of Ultra-Bright ZAIS NPs}

In another aspect, we synthesized $\mathrm{ZnS}-\mathrm{AgInS}_{2}$ nanocrystals, termed as ZAIS, through premixing In and $\mathrm{Zn}$ precursors with sulfur, followed by injection of silver precursors. The
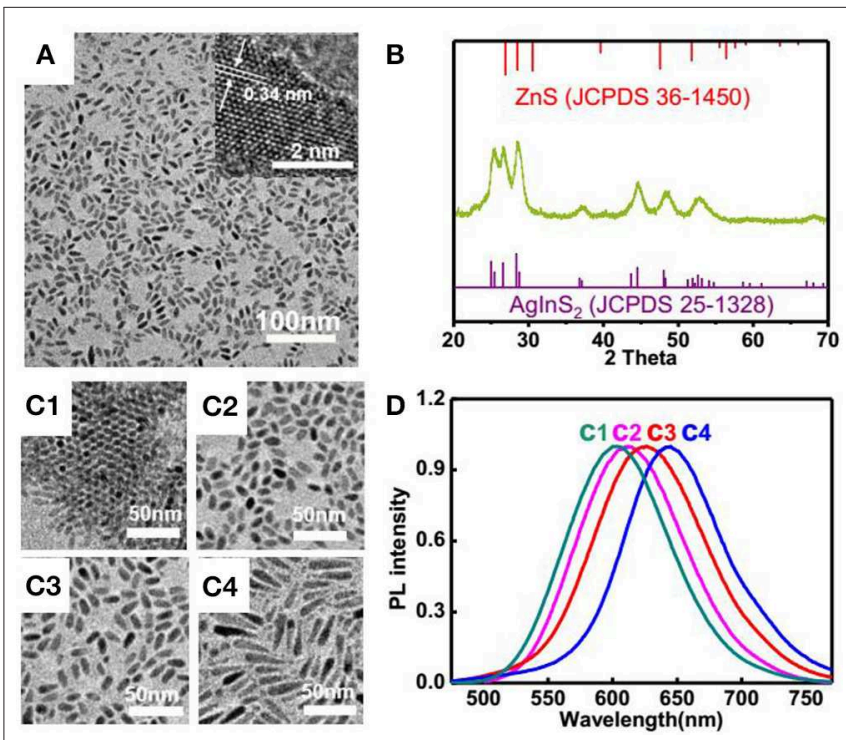

FIGURE 3 | (A) TEM and HRTEM (inserted) images and (B) XRD patterns of ZAIS nanoparticles; (C) TEM images of ZAIS with different dosages of sulfur: (C1) $1.6 \mathrm{mg}$; (C2) $2.4 \mathrm{mg}$; (C3) $4.8 \mathrm{mg}$; (C4) $9.6 \mathrm{mg}$; (D) Normalized photoluminescence spectra of ZAIS with different dosages of sulfur. 
TEM image displayed a uniform rod-like structure and HRTEM presented a continuous lattice fringes throughout the particles with interplanar space of $0.34 \mathrm{~nm}$ (Song et al., 2016), suggesting a typical solid solution of ZAIS, which is consistent with observation of corresponding XRD patterns, shown in Figures $3 \mathrm{~A}, \mathbf{B}$ considering that the main peaks located in between that of $\mathrm{ZnS}$ and $\mathrm{AgInS}_{2}$ (Torimoto et al., 2007). It shall be noted that most of ZAIS reported in the literature have a spherical structure and for preparation of ZAIS with anisotropic shapes (Xie et al., 2009), it normally leaded to a mixture of particles with different shapes. Here, the afforded ZAIS display a uniform rod-like structure. In contrast to reported protocols that always directly mixed up all the corresponding metal salts at first hand, we premix indium and zinc salt with sulfur powder, followed by introduction of silver precursor. It is anticipated that the silver ion has strongest tendency for interaction with sulfur and adding it at later stage would afford more uniform nucleation, which then facilitate formation of uniform rod-like structure. Moreover, the morphologies could be readily modulated with the dosages of sulfur, as evidenced in Figure $\mathbf{3 C}$ and the emission peak wavelength showed a red-shift along the increase of sulfur dosage (Figure 3D). The resulting ZAIS nanocrystals displayed a high quantum yield, measured to be $78.9 \%$, as shown in Supplementary Figure 7, with a long luminescence lifetime of $1.5 \mu \mathrm{s}$, which hold great potentials in terms of bioimaging.

\section{Stability and Cytotoxicity ZAIS@PCDA-BA NCs}

Considering the excellent biocompatibility of ZAIS nanocrystals, here PCDA-BA were employed to transfer hydrophobic ZAIS into aqueous solution and meanwhile, introduced as targeting moieties. Following the as-reported protocols, ZAIS nanocrystals were mixed with PCDA and PCDA-BA under sonication treatment, followed by light irradiation. Similar to other nanoparticles, the TEM image of resulting nanocomposites (Supplementary Figure 8) indicated a monodispersed feature without aggregation and DLS results suggested a slight increase of hydrodynamic particle size after surface modification (Figures 4a,b). Though it has been reported polymerized PCDA backbone would induce a color change, here judging from the emission properties of ZAIS@PCDA-BA NCs, apparently it caused negligible effect on emission properties, shown in Supplementary Figure 9.

Moreover, the afforded hydrophilic ZAIS@PCDA-BA NCs are very stable as their fluorescence and size changes are wellmaintained for over 3 weeks, as shown in Figure 4c. Prior to cell imaging, the cytotoxicity of ZAIS-BA NCs was tested by the MTT assay. As implied in Figure 4d, the results suggested that the cell viability maintained over $90 \%$ even after $48 \mathrm{~h}$ under the highest concentration $(300 \mu \mathrm{g} / \mathrm{mL})$, implying good biocompatibility of ZAIS@PCDA-BA NCs.
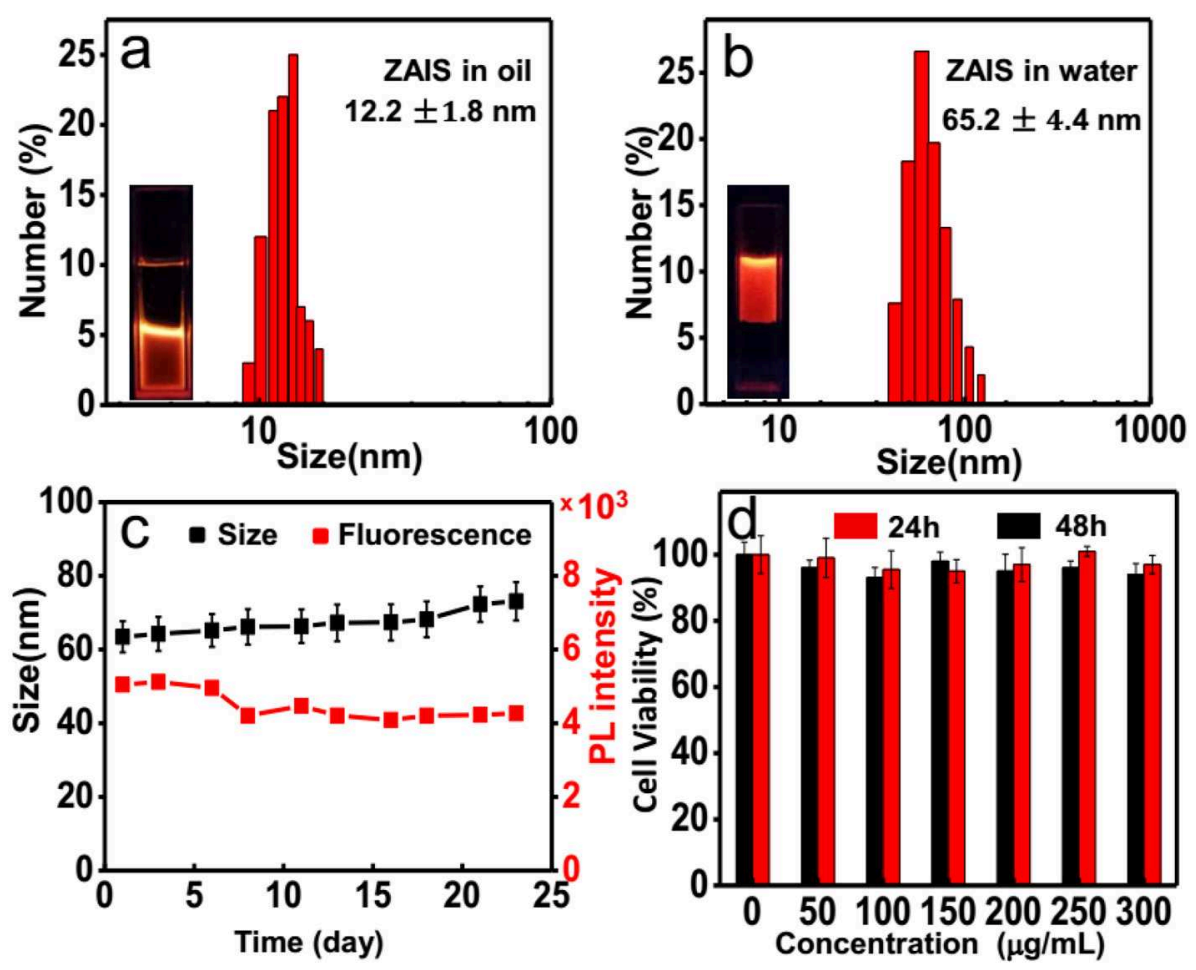

FIGURE 4 | DLS results for the ZAIS@PCDA-BA NCs (a) before and (b) after surface modification. (c) Size distribution and photoluminescence intensity changes of ZAIS@PCDA-BA NCs along with time. (d) Cell viability tests of ZAIS@PCDA-BA NCs on HepG2 cell lines at different concentrations after incubation for $24 \mathrm{~h}$ (red) and $48 \mathrm{~h}$ (black), respectively. 


\section{Cell Imaging of ZAIS@PCDA-BA NCs}

Given that cancerous cells are known to overexpress sialic acid moieties on cell membrane surface, here the capacity of luminescent ZAIS@PCDA-BA NCs for selectively target cancer cells was explored. Initially, luminescent ZAIS@PCDA-BA NCs were incubated with cells for different time intervals and clearly it was found that as incubation time increased, more and more ZAIS@PCDA-BA NCs attached on the surface of cells, suggested by the gradually increased luminescent intensities, evidenced by Supplementary Figure 10. When incubation time increase to $12 \mathrm{~h}$, endocytosis occurred (Supplementary Figure 11) since the whole cell were lighten up. Then, luminescent ZAIS with and without PCDA-BA modification were incubated with HepG2 cells. As shown in Figure 5a, the ZAIS nanocrystals that have PCDA-BA moieties on surface could specifically labeling on the membrane of HepG2 cells after incubation for $8 \mathrm{~h}$. As for the control group in Figure 5b, it is hardly to observe luminescence, further demonstrating the selective targeting ability of PCDA-BA moieties toward cancerous cell membranes. In another aspect, ZAIS@PCDA-BA NCs were incubated with normal cell lines (HUVEC cells). Clearly, it is hardly to observe luminescence emission, as shown in Supplementary Figure 12, suggesting that ZAIS@PCDA-BA NCs displayed low affinity toward normal cells, which was reasonable since saccharide residues are only overexpressed in cancerous cells. In addition, it is known that boronic acid could bind with monosaccharide, which, we assumed, would have a competitive binding with sialic acid moieties on the cell surface. In this regard, we incubated ZAIS@PCDA-BA NCs with HepG2 cells in the presence of Dfructose, displayed as in Figure 5c, clearly the high concentration of D-fructose $(0.1 \mathrm{M})$ would induce an off-targeting effect of ZAIS@PCDA-BA NCs toward cell membranes.

\section{CONCLUSIONS}

In summary, we have developed a general and facile method for hydrophobic nanoparticles surface engineering with various shapes, sizes, and chemical compositions. By taking advantage of the in-situ polymerization of PCDA, we obtained surface functionalized nanocomposites with high stability in aqueous solution without obvious changing in proprieties such as luminescence, optical and magnetism. In addition, owing to the carboxylic group of PCDA, the functionalized nanocrystals are biocompatibility and bioconjugatable. As a proof-ofconcept, PCDA-BA was used to functionalize ZAIS nanocrystals, which then was used for specific labeling cancerous cells.

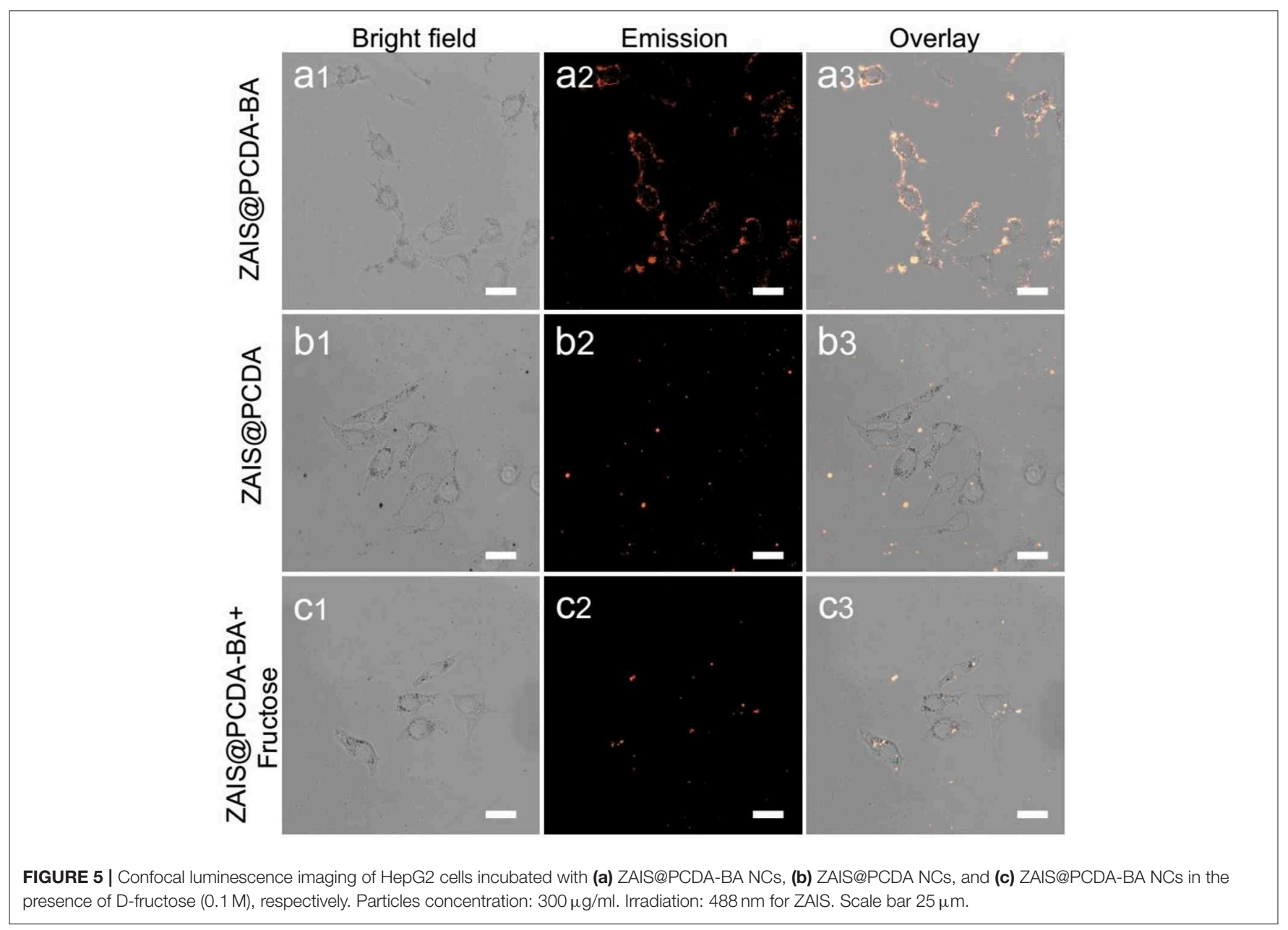


The method is simple and versatile, thus can be used as a general method for surface engineering of hydrophobic inorganic nanocrystals.

\section{DATA AVAILABILITY STATEMENT}

The raw data supporting the conclusions of this manuscript will be made available by the authors, without undue reservation, to any qualified researcher.

\section{AUTHOR CONTRIBUTIONS}

SG performed all the experiments. CG helped with the cell imaging experiments. HW and GT helped with the nanoparticle synthesis. SX drafted the manuscript. SX and LW supervised the project and were in charge of overall direction of the project. All authors contributed to the final version of the manuscript. All the authors have agreed with the manuscript for submission.

\section{REFERENCES}

Arshad, A., Chen, H. L., Bai, X. L., Xu, S. Y., and Wang, L. Y. (2016). Onepot aqueous synthesis of highly biocompatible near infrared $\mathrm{CuInS}_{2}$ quantum dots for target cell imaging. Chin. J. Chem. 34, 576-582. doi: 10.1002/cjoc.2015 00777

Chen, G., Tian, F., Li, C., Zhang, Y., Weng, Z., Zhang, Y., et al. (2015). In vivo real-time visualization of mesenchymal stem cells tropism for cutaneous regeneration using NIR-II fluorescence imaging. Biomaterials 53, 265-273. doi: 10.1016/j.biomaterials.2015.02.090

Chen, X., Kang, S., Kim, M. J., Kim, J., Kim, Y. S., Kim, H., et al. (2010). Thin-film formation of imidazolium-based conjugated polydiacetylenes and their application for sensing anionic surfactants. Angew. Chem Int. Ed. 49, 1422-1425. doi: 10.1002/anie.200905041

Chen, Y., Thakar, R., and Snee, P. T. (2008). Imparting nanoparticle function with size-controlled amphiphilic polymers. J. Am. Chem. Soc. 130, 3744-3745. doi: $10.1021 /$ ja711252n

Choi, K. Y., Yoon, H. Y., Kim, J.-H., Bae, S. M., Park, R.-W., Kang, Y. M., et al. (2011). Smart nanocarrier based on PEGylated hyaluronic acid for cancer therapy. ACS Nano 5, 8591-8599. doi: 10.1021/nn202070n

Deng, M., Nina, T., Bai, F., and Wang, L. (2012). Surface functionalization of hydrophobic nanocrystals with one particle per micelle for bioapplications. Chem. Mater. 24, 2592-2597. doi: 10.1021/cm301285g

Dong, A., Ye, X., Chen, J., Kang, Y., Gordon, T., Kikkawa, J. M., et al. (2011). A generalized ligand-exchange strategy enabling sequential surface functionalization of colloidal nanocrystals. J. Am. Chem. Soc. 133, 998-1006. doi: $10.1021 /$ ja108948z

Guo, C., Xu, S. Y., Arshad, A., and Wang, L. Y. (2018). A pH-responsive nanoprobe for turn-on F-19-magnetic resonance imaging. Chem. Commun. 54, 9853-9856. doi: $10.1039 / \mathrm{c} 8 \mathrm{cc} 06129 \mathrm{~g}$

Guo, C., Zhang, Y. Y., Li, Y. W., Xu, S. Y., and Wang, L. Y. (2019). F-19 MRI nanoprobes for the turn-on detection of phospholipase A2 with a low background. Anal. Chem. 91, 8147-8153. doi: 10.1021/acs.analchem.9b00435

Huang, S., Bai, M., and Wang, L. (2013). General and facile surface functionalization of hydrophobic nanocrystals with Poly(amino acid) for cell luminescence imaging. Sci. Rep. 3:2023. doi: 10.1038/srep02023

Hui, Y., Yi, X., Hou, F., Wibowo, D., Zhang, F., Zhao, D., et al. (2019). Role of nanoparticle mechanical properties in cancer drug delivery. ACS Nano 13, 7410-7424. doi: 10.1021/acsnano.9b03924

Lee, J., Jun, H., and Kim, J. (2009). Polydiacetylene-liposome microarrays for selective and sensitive Mercury(II) detection. Adv. Mater. Weinheim. 21, 3674-3677. doi: 10.1002/adma.200900639

\section{FUNDING}

This research was supported in part by the National Natural Science Foundation of China (21874007, 21505003, and 21521005) and the Fundamental Research Funds for the Central Universities (XK1901, PYBZ1827, buctrc201812, buctrc201815, and XK1802-6).

\section{ACKNOWLEDGMENTS}

We also thank the support from the Public Hatching Platform for Recruited Talents of Beijing University of Chemical Technology.

\section{SUPPLEMENTARY MATERIAL}

The Supplementary Material for this article can be found online at: https://www.frontiersin.org/articles/10.3389/fchem. 2019.00734/full\#supplementary-material

Lee, K. M., Moon, J. H., Jeon, H., Chen, X., Kim, H. J., Kim, S., et al. (2011). Diverse colorimetric changes of polydiacetylenes with cationic surfactants and their mechanistic studies. J. Mater. Chem. 21, 17160-17166. doi: 10.1039/cljm12818c

Li, S., Yan, Z., Luo, Z., Xu, Y., Huang, F., Hu, G., et al. (2019). Directional and rotational motions of nanoparticles on plasma membranes as local probes of surface tension propagation. Langmuir 35, 5333-5341. doi: 10.1021/acs.langmuir.9b00225

Liu, A., Peng, S., Soo, J. C., Kuang, M., Chen, P., and Duan, H. (2011). Quantum dots with phenylboronic acid tags for specific labeling of sialic acids on living cells. Anal. Chem. 83, 1124-1130. doi: 10.1021/ac1028853

Liu, Y., Zhou, S., Tu, D., Chen, Z., Huang, M., Zhu, H., et al. (2012). Aminefunctionalized lanthanide-doped zirconia nanoparticles: optical spectroscopy, time-resolved fluorescence resonance energy transfer biodetection, and targeted imaging. J. Am. Chem. Soc. 134, 15083-15090. doi: 10.1021/ja306066a

Lu, J., Chen, Y., Liu, D., Ren, W., Lu, Y., Shi, Y., et al. (2015). One-step protein conjugation to upconversion nanoparticles. Anal. Chem. 87, 10406-10413. doi: 10.1021/acs.analchem.5b02523

Lu, X. Q., Li, Y. B., Bai, X. L., Hu, G. F., and Wang, L. Y. (2017). Multifunctional $\mathrm{Cu}_{1.94} \mathrm{~S}-\mathrm{Bi}_{2} \mathrm{~S}_{3} @$ polymer nanocomposites for computed tomography imaging guided photothermal ablation. Sci. China Mater. 60, 777-788. doi: 10.1007/s40843-017-9068-6

Lu, Z., Gao, C., Zhang, Q., Chi, M., Howe, J. Y., and Yin, Y. (2011). Direct assembly of hydrophobic nanoparticles to multifunctional structures. Nano Lett. 11, 3404-3412. doi: 10.1021/nl201820r

Mahmoudi, K., and Hadjipanayis, C. G. (2014). The application of magnetic nanoparticles for the treatment of brain tumors. Front. Chem. 2:109. doi: 10.3389/fchem.2014.00109

Matsumoto, A., Cabral, H., Sato, N., Kataoka, K., and Miyahara, Y. (2010). Assessment of tumor metastasis by the direct determination of cellmembrane sialic acid expression. Angew. Chem Int. Ed. 49, 5494-5497. doi: 10.1002/anie.201001220

Nifontova, G., Ramos-Gomes, F., Baryshnikova, M., Alves, F., Nabiev, I., and Sukhanova, A. (2019). Cancer cell targeting with functionalized quantum dot-encoded polyelectrolyte microcapsules. Front. Chem. 7:34. doi: $10.3389 /$ fchem.2019.00034

Nishiyabu, R., Kubo, Y., James, T. D., and Fossey, J. S. (2011). Boronic acid building blocks: tools for sensing and separation. Chem. Commun. 47, 1106-1123. doi: 10.1039/c0cc0 2920c

Nsubuga, A., Zarschler, K., Sgarzi, M., Graham, B., Stephan, H., and Joshi, T. (2018). Towards utilising photocrosslinking of polydiacetylenes for the preparation of "Stealth" upconverting nanoparticles. 
Angew. Chem Int. Ed. 57, 16036-16040. doi: 10.1002/anie.2018 11003

Nurunnabi, M., Cho, K. J., Choi, J. S., Huh, K. M., and Lee, Y.-H. (2010). Targeted near-IR QDs-loaded micelles for cancer therapy and imaging. Biomaterials 31, 5436-5444. doi: 10.1016/j.biomaterials.2010.03.057

Song, J., Cheng, Q., Kopta, S., and Stevens, R. C. (2001). Modulating artificial membrane morphology: $\mathrm{pH}$-induced chromatic transition and nanostructural transformation of a bolaamphiphilic conjugated polymer from blue helical ribbons to red nanofibers. J. Am. Chem. Soc. 123, 3205-3213. doi: $10.1021 /$ ja0035046

Song, J., Ma, C., Zhang, W., Li, X., Zhang, W., Wu, R., et al. (2016). Bandgap and structure engineering via cation exchange: from binary Ag2S to ternary AgInS2, quaternary AgZnInS alloy and AgZnInS/ZnS Core/shell fluorescent nanocrystals for bioimaging. ACS Appl. Mater. Interfaces 8, 24826-24836. doi: 10.1021/acsami.6b07768

Sun, X., James, T. D., and Anslyn, E. V. (2018). Arresting "loose bolt" internal conversion from $-\mathrm{B}(\mathrm{OH})(2)$ groups is the mechanism for emission turn-on in ortho-aminomethylphenylboronic acid-based saccharide sensors. J. Am. Chem. Soc. 140, 2348-2354. doi: 10.1021/jacs.7b12877

Sun, Y., Gao, W., Liu, Z., Yang, H., Cao, W., Tong, L., et al. (2019). A LRET-based luminescence nanoprobe for in situ imaging of CD36 activation and CD36-oxLDL binding in atherogenesis. Anal. Chem. 91, 9770-9776. doi: 10.1021/acs.analchem.9b01398

Torimoto, T., Adachi, T., Okazaki, K.-I., Shibayama, S. M., Ohtani, T., Kudo, B., et al. (2007). Facile synthesis of ZnS-AgInS2 solid solution nanoparticles for a color-adjustable luminophore. J. Am. Chem. Soc. 129, 12388-12389. doi: $10.1021 /$ ja0750470

Vines, J. B., Yvon, J.-H., Ryu, N.-E., Lim, D.-J., and Park, H. (2019). Gold nanoparticles for photothermal cancer therapy. Front. Chem. 7:167. doi: $10.3389 /$ fchem.2019.00167

Wang, H., Zhong, L., Liu, Y., Xu, X., Xing, C., Wang, M., et al. (2018). A black phosphorus nanosheet-based siRNA delivery system for synergistic photothermal and gene therapy. Chem. Commun. 54, 3142-3145. doi: $10.1039 /$ c8cc00931g

Wang, X., Yue, D., Lv, E., Wu, L., and Qin, W. (2014). Reporter-free potentiometric sensing of boronic acids and their reactions by using quaternary ammonium salt-functionalized polymeric liquid membranes. Anal. Chem. 86, 1927-1931. doi: $10.1021 /$ ac500028v

Wen, J. T., Bohorquez, K., and Tsutsui, H. (2016). Polydiacetylene-coated polyvinylidene fluoride strip aptasensor for colorimetric detection of zinc(II). Sens. Actuators B 232, 313-317. doi: 10.1016/j.snb.2016.03.118
Wu, P., Pan, J.-B., Li, X.-L., Hou, X. J.-Xu, J., and Chen, H.-Y. (2015). Long-lived charge carriers in Mn-Doped CdS quantum dots for photoelectrochemical cytosensing. Chem. Eur. J. 21, 5129-5135. doi: 10.1002/chem.2014 05798

Xie, R., Rutherford, M., and Peng, X. (2009). Formation of high-quality I-III-VI semiconductor nanocrystals by tuning relative reactivity of cationic precursors. J. Am. Chem. Soc. 131, 5691-5697. doi: 10.1021/ja9005767

Xu, S.-Y., Ruan, Y.-B., Luo, X.-X., Gao, Y.-F., Zhao, J.-S., Shen, J.-S., et al. (2010). Enhanced saccharide sensing based on simple phenylboronic acid receptor by coupling to Suzuki homocoupling reaction. Chem. Commun. 46, 5864-5866. doi: 10.1039/c0cc01019g

Yan, R., Hu, Y., Liu, F., Wei, S., Fang, D., Shuhendler, A. J., et al. (2019). Activatable NIR Fluorescence/MRI bimodal probes for in vivo imaging by enzyme-mediated fluorogenic reaction and self-assembly. J. Am. Chem. Soc. 141, 10331-10341. doi: 10.1021/jacs.9b03649

Zhang, H., Liu, K., Li, S., Xin, X., Yuan, S., Ma, G., et al. (2018). Self-assembled minimalist multifunctional theranostic nanoplatform for magnetic resonance imaging-guided tumor photodynamic therapy. Acs Nano 12, 8266-8276. doi: 10.1021/acsnano.8b03529

Zhao, M., Li, H., Li, H., Qiao, Q., Cao, C., and Xu, Z. (2015). A turn-on fluorescent probe for hydrogen sulfide and its application in living cells. RSC Adv. 5, 86355-86358. doi: 10.1039/c5ra15384k

Zhao, T., Nam-Trung, N., Xie, Y., Sun, X., Li, Q., and Li, X. (2017). Inorganic nanocrystals functionalized mesoporous silica nanoparticles: fabrication and enhanced bio-applications. Front. Chem. 5:118. doi: 10.3389/fchem.2017.00118

Zhu, K., Ju, Y., Xu, J., Yang, Z., Gao, S., and Hou, Y. (2018). Magnetic nanomaterials: chemical design, synthesis, and potential applications. Acc. Chem. Res. 51, 404-413. doi: 10.1021/acs.accounts. $7 \mathrm{~b} 00407$

Conflict of Interest: The authors declare that the research was conducted in the absence of any commercial or financial relationships that could be construed as a potential conflict of interest.

Copyright (c) 2019 Gu, Guo, Wang, Tian, Xu and Wang. This is an open-access article distributed under the terms of the Creative Commons Attribution License (CC BY). The use, distribution or reproduction in other forums is permitted, provided the original author(s) and the copyright owner(s) are credited and that the original publication in this journal is cited, in accordance with accepted academic practice. No use, distribution or reproduction is permitted which does not comply with these terms. 